\title{
Prüfung des Jodkaliums auf kohlensaures und jodsaures Kali.
}

Das Jodkalium ist nie chemisch rein im Handel. Eine Verbindung, die aus gleichen Aequivalenten Jod und Kalium bestände, wie die Theorie anzeigt, hätte keine dauerhafte Farbe und würde sich rasch gelb färben durch Einwirkung des Sauerstoffs und der Kohlensäure in der Luft. Die beständige weisse Farbe verdankt das kaustische Jodkalium einem kleinen Ueberschuss von kohlensaurem Kali; ausserdem tindet sich auch häufig jodsaures Kali darin.

Zur Entdeckung derselben verfährt W. Copney folgendermaassen.

Er macht eine Lösung des verdüchtigen Jodürs in einer kleinen Menge destillirten Wassers und giesst einige Tropfen Kisenjodïrsyrup hincin. Bei Gegenwart von kohlensaurem Kali bildet sich ein blauer Niederschlag, dessen Farbe einige Zeit unveründert bleibt. War zugleich' jodsaures Kali vorhanden, so wird der blaue Niederschlag rasch roth.

Um den Werth der neuen Reaction zu prüfen, hat (op) ney selbst sich reines Jodkalium dargestellt, womit er wie oben angegeben verfuhr. Er crhielt selbst nach 48 situnden keine Spur von Niederschlag. Aber bei $\mathrm{Zn}$ satz eines einzigen Tropfens einer Lösung von 1 Gran kohlensaurem Kali in 1000 Gran Wasser bildete sich augenblicklich ein blauer Niederschlag.

Fine zweite Probe, die koblensaures und jodsaures Kali zugleich enthielt, gab bei Zusatz des Reagens einen Niederschlag, dessen anfangs blaue Fiarbe rasch roth wurde.

Eine dritte Probe, die nur jodsaures Kali enthielt, gab sofort einen rothen Niederschlag. (Journ. de Pharm. et de Chim. Août 1856.) A. $O$.

\section{Veher arsenige Säure im Vitriolöl.}

Nach Cameron's Beobachtungen hatte sich in Flaschen, die 8 Pfund Vitriolöl enthielten, in jeder ungefähr 1 Unze arsenige Süure in octaëdrischen Krystallen ausgeschieden. Die Säure war offenbar aus sehr arsenhaltigem Schwefelkies bereitet, die Menge arseniger S̈̈ure, welche in käuflicher Schwefelsäure vorkommen kann, ist also sehr beträchtlich. (Chem. Gaz. 1856.) B. 